\title{
A new bioenergy crop based on oil-rich seeds from the legume tree Pongamia pinnata
}

This article was published in the following Dove Press journal:

Energy and Emission Control Technologies

19 July 2017

Number of times this article has been viewed

\section{Peter M Gresshoff' \\ Latha Rangan ${ }^{2}$ \\ Arief Indrasumunar' \\ Paul T Scott'}

'Centre for Integrative Legume Research, School of Agriculture and Food Sciences, The University of Queensland, St Lucia, Brisbane, QLD, Australia; ${ }^{2}$ Department of Biosciences and Bioengineering, Indian Institute of Technology Guwahati, Assam, India

Correspondence: Peter M Gresshoff Centre for Integrative Legume Research, School of Agriculture and Food Sciences, The University of Queensland, St Lucia, Brisbane, QLD 4072, Australia Email p.gresshoff@uq.edu.au
Abstract: Any informed discussion on the future sources of energy in our world requires the consideration of renewable biofuels. These are produced by biological processes, such as plant growth based on photosynthesis and microbes using waste products from diverse origins. Many biofuels, such as ethanol produced from plants like sugarcane, are seen as sustainable, such paradigms should be critically analyzed in terms of total inputs. The legume tree Pongamia pinnata (also called Millettia pinnata) offers a substantiated opportunity for a sustainable biofuel feedstock. It is characterized by fast plant growth, broad tropical and subtropical growth habitat, and high annual yields of oil-rich seed. Annual yield of the seed-extracted oil, rich in the monounsaturated fatty acid oleic acid (C18:1), is between 1,000 and 5,000 L/ha, depending on local conditions, including rainfall, temperature, and soil. It can be burnt in bioenergy generators to yield electrical output. It can also be converted to biodiesel by transesterification for transportation and industrial use. Conversion to aviation jet fuel by hydrogenation and subsequent purification is also possible. The legume nature of the plant allows it to harbor nitrogen-fixing soil bacteria (broadly called "rhizobia") in newly induced root organs called nodules. This symbiosis makes the energy inputs considerably less than those seen with nitrate fertilizer - requiring biofuel feedstocks, such as corn, sugarcane, and canola. Combined with general characteristics of plant, such as abundant seed set and large oil-rich seed, secondary products, such as seed meal and vigorous growth characteristics, make this tree an excellent candidate for sustainable bioenergy production in many parts of the globe.

Keywords: biofuel, biotechnology, legume, plant growth, renewables, sustainability

\section{Introduction}

The global economy is faced with the fact of increasing human population, increased per capita energy and food consumption, and global environmental degradation, increased urbanization and resultant decreased availability of agricultural land. ${ }^{1-3}$ These predicted scenarios make for a troubled planet within the next 40 years or so. Major mishaps such a pandemic disease and military conflict may alter the projections, but neither of these is really of long-term effect. Thus, we all need to look at processes and actions aimed at lessening, perhaps even eradicating problems associated with global environmental quality, global fuel security, and global food security. ${ }^{4,5}$

The reader is reminded of the difference between the terms energy and fuel. To a large degree, energy, such as electricity, is not easily stored, while fuel is a form of stored energy. Technological advances in battery design are warranted, which is currently the subject of increased research activity. Innovative processes for electricity retention, such as water being pumped at low-demand periods to elevated dams/reservoirs and submit your manuscript | www. dovepress.com

Dovepress

http://dx.doi.org/10.2147/EECT.S69854
Energy and Emission Control Technologies 2017:5 19-26 19

(c) (i) (8) ( 2017 Greshhoff et al. This work is published and licensed by Dove Medical Press Limited. The full terms of this license are available at https://www.dovepress.com/ BY terms.php and incorporate the Creative Commons Attribution - Non Commercial (unported, v3.0) License (http://(reativecommons.org/licenses/by-nc/3.00). By accessing the (the work is properly attributed. For permission for commercial use of this work, please see paragraphs 4.2 and 5 of our Terms (https://www.dovepress.com/terms.php) 
then used to generate electrical power in high-demand times, are useful but not globally applicable.

Electrical energy as a replacement of liquid fossil fuels is highly attractive. This is illustrated by the large-scale conversion of rail transportation via electrification of lines and increased economic and social focus on electric cars. Electric energy relies at present on the generation from a variety of sources, such as coal, oil, wind, sun, ocean tides, dams, and nuclear fission. Future technological developments may lead to fusion-based power generation. Some of these sources are more sustainable and have less impact on the environment than fossil sources of energy. Thus, coal is not highly desired because of major emissions of the greenhouse gas carbon dioxide $\left(\mathrm{CO}_{2}\right)$, particulate soot, and gaseous sulfur-containing compounds leading to acidification of soil. Moreover, coal is used globally, because of the existence of a century-old technology, its adoption, and ample supplies resulting in low consumer prices. Nuclear fission-generated electricity, in contrast, has a high demand for infrastructure (construction, maintenance, and security) and associated concerns with environmental and public safety. Photoelectric collection of solar energy has an immense attraction but requires concern over cost-benefit balances of life cycle and issues of infrastructure recovery/waste recovery upon equipment (ie, solar panels failure, even if only after 15-25 years of use). What are we to do with the anticipated millions of photovoltaic panels with irreversible damage from domestic and industrial use? What is the cost of such recovery program? The same concern for costs of maintenance and equipment recycling can be raised for wind-powered turbines.

No matter what the concerns are about the range of energy-producing technologies, we note that most technologies produce electrical energy for heating/cooling, transportation, electric motors, and communication devices (TV, computers, telephones, etc), that cannot be stored midto long-term. This situation leaves a supply gap for several energy-requiring sectors. The major one is aviation, as it is more or less impossible to use electricity (whether battery stored, solar panel generated, or nuclear powered) to fly across major oceans in a reasonable amount of time or with a substantial payload. Likewise not all energy use is connected to existing electrical grids. Worldwide, there are abundant mining and construction activities, along with more isolated urban settlements that receive electrical energy via trucked or even barged liquid fossil fuel, which then is converted via gas turbines.

Current literature and discussions for new energy and fuel technology emphasize terms like renewable and sustainable.
This is in contrast to fuels based on limited liquid fossil fuels. Estimates vary but global fossil oil reserves in 2015 were estimated to be $\sim 260$ trillion $\mathrm{L}^{6}$ (1,700 billion barrels) up to $24 \%$ from the 2004 estimate of 160 trillion L. ${ }^{7}$ Globally, we presently use $\sim 4$ trillion $\mathrm{L}$ of fossil oil/year (70 million barrels of oil/d), meaning that more or less 50 years of reserves are left. With increasing world population and altered, more energyintensive life styles, consumption is predicted to rise, although alternative energy sources may counteract that prediction. These values assume many sociological, environmental, and technical parameters, which may change. New oil supplies (possibly in environmentally sensitive and protected areas like the Arctic and Antarctic) may be discovered, new oil extraction methods (like the controversial fracking) may increase yield, and alternative energy sources (like liquid fuels made from solids such as coal, waste, or biomass) will no doubt become more productive and thus may be exploited.

This review is not meant to discuss the issues of peak oil, although it has to be clearly stated that the present pool of crude oil supply will eventually diminish, necessitating a new broad-scale economy of novel fuels. Thus, a sustainable source of locally available, biomass-derived feedstock for generation of biofuels is needed.

Such biofuels have another, often underemphasized, advantage namely that they can be produced locally at the site of consumption. For example, many mining sites and townships in Western Australia and Queensland are not part of major power grids, demanding that fuel is transported by road, rail, or sea to be converted to electricity at local generation facilities. ${ }^{8}$ Many of these locations have the capacity to grow biofuel crops tolerant to environmental stresses with low nitrogen fertilizer demand. Shortages of necessary irrigation water can be satisfied by desalination or subterranean aquifers.

One such fuel is biodiesel produced through transesterification, which combines plant oil with an excess of methanol and a catalyst (sodium or potassium hydroxide) to produce glycerol and a mixture of fatty acid monoalkyl methyl esters. In 2011, > 11 million ha of land were used globally to produce biodiesel. Biodiesel is presently produced from oil seed crops such as soybeans, oil palm, rapeseed, and canola. Approximately $50 \%$ of the biodiesel factories have a production output of $<35$ million L/year, using a variety of waste feedstocks (eg, used cooking oil, animal fats, greases), while the other half ranges in output size from 40 million to $>150$ million L/year, using oil seed feedstocks. One notes that the larger sized facilities utilize integrated soybean production and biodiesel plants (eg, in Indiana, USA, and Argentina). Current average 
rapeseed biodiesel production in the European Union is $1,300 \mathrm{~L} / \mathrm{ha}$ from an average seed yield of $3.1 \mathrm{ton} / \mathrm{ha}$. Current average palm oil yield is 4,200 L/ha from the higher average yield of $>18$ ton/ha in Malaysia. ${ }^{1}$

Sadly, oil palm and canola/rapeseed are not nitrogenfixing legumes and thus require extensive nitrogen fertilization (up to $200 \mathrm{~kg}$ of nitrogen/ha/year). This fertilizer need implies production and transportation as well as environmental costs due to run-off (causing surface water eutrophication) and atmospheric pollution caused by nitrous oxide (a strong greenhouse gas) production; ${ }^{9,10}$ soybean, in contrast, being a legume, has the ability to form nitrogen-fixing nodules on its roots for growth and seed development, ${ }^{11}$ although its major worldwide food/feed status should discourage its application as a biofuel feedstock.

Globally, a large number of suppliers of smaller size biodiesel production capacities range from $\sim 1$ ton/d to 500 times that, using various waste feedstocks, such as animal fat, waste cooking oils, and greases, and some of the nonfood oils.

Biodiesel and customized oil compositions can also be manufactured from sugars, using modified organisms, including heterotrophic algae. Microalgae and cyanobacteria can generate fatty acids using sugars as feedstock from which biodiesel or other hydrocarbon fuels can be derived. Ongoing research with these organisms aims to use brackish waters and land that does not conflict with food production but will require improvements in engineering, nitrogen nutrition, and reduction in costs before economically viable and sustainable systems are commercialized. ${ }^{12}$

Here we summarize the advances made with the legume tree Pongamia pinnata, from its centuries-old uses as a provider of lantern and stove fuel in India and neighboring regions to its present day use as a biofuel crop capable of growing on marginal land. ${ }^{3}$ This latter property is essential as global food production (fueled by increasing population, per capita food consumption, demand for quality, and associated spoilage) demands access to fertile and cultivable land, avoiding competition with biofuel crops. Thus, use of food plants or land needed for food production is not defendable for the development of biofuel feedstocks. The valid food vs fuel debate must not be overlooked when considering issues of sustainability and suitability. ${ }^{9}$

\section{Pongamia root nodulation and symbiotic nitrogen fixation}

The plant is a legume (like soybean, clover, peanut, and acacia) and as such is capable of symbiotic nitrogen fixation through root nodulation ${ }^{13,14}$ (Figure 1A). Significantly, it is a tree and as such large and long-lived, with annual harvests of its oil-rich seeds (Figure 1B). Nodules form on roots within 15-20 days after inoculation with soil bacteria broadly belonging to the Bradyrhizobium category of legume symbionts. Even soybean-compatible strains, like Bradyrhizobium japonicum USDA110 and CB1809, will participate as active symbionts, although recent studies have isolated superior strains presently undergoing characterization (NemenzoCalica et al, unpublished data, 2016). ${ }^{15}$ Biological nitrogen fixation of pongamia nodules was verified by enhanced growth and pink/red coloration of nodule interiors (caused by the oxygen transport protein leghemoglobin) compared with uninoculated controls and by the short-term assay based on acetylene reduction. Although quantified in the short term, further research needs to determine the long-term proportion of nitrogen input for pongamia growth and seed yield.

\section{Salinity tolerance}

Pongamia grows rapidly in a large variety of climates (ie, from tropical Queensland far north Cooktown to southeastern regions around Brisbane). Typically, it is considered a tropical plant, often found close to marine environments, such as inlets, river mouths, and sea fronts. Trees show a strong tolerance to ocean salinity, confirmed by laboratory/ greenhouse pot trials. Indeed, the plant will tolerate an electric conductivity of $20 \mathrm{dS} / \mathrm{m}$ (equivalent to $20 \mathrm{mS} / \mathrm{cm}$ or $220 \mathrm{NaCl}$ ), growing perfectly well at $10 \mathrm{dS} / \mathrm{m}$. Note that average ocean water has a salt content of $350 \mathrm{mM}$. The upper limit of salinity recommended for human consumption is $8.3 \mathrm{dS} / \mathrm{m}(8 \mathrm{mM} \mathrm{NaCl})$, while for irrigation of salt-sensitive crop species like soybeans is $\sim 4-6 \mathrm{dS} / \mathrm{m}$. Some preliminary experiments suggest that low salt stimulates growth of pongamia seedlings compared with no salt. This tolerance may allow efficient seed distribution via ocean currents, although pongamia seeds have been found to lose germination ability after 6 months. Seed distribution via ocean currents is likely to be a major mechanism as animal distribution of the seed (weighing between 1.0 and $3.0 \mathrm{~g}$; with the rigidly, woody pod wall of equivalent mass) is unlikely because seed predation has not been widely observed. Indeed, the authors invite the reader to communicate on known and verified pongamia seed predators.

\section{Seed and pod development}

Usually pongamia develops only one seed per mature pod; however, two ovaries per pod exist, and some trees have the preference of paired fertilization and seed development. Such double-seeded pods usually do not have more seed 

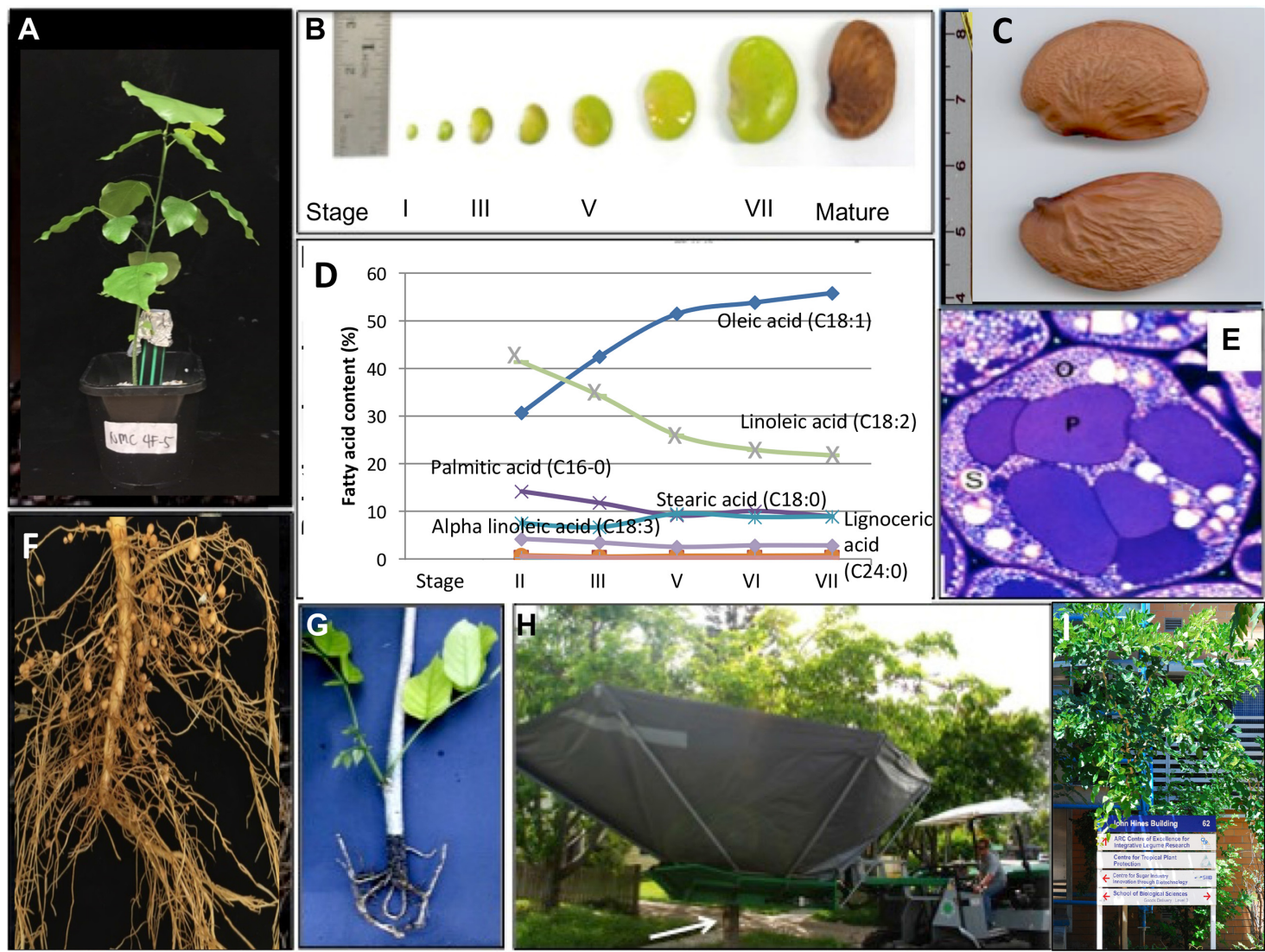

Figure I Biology of Pongamia pinnata.

Notes: (A) Pongamia pinnata seedling emerging in pot. Note how the seed halves (cotyledons) remain at the soil surface; hence the stem is epicotyl. Overall plant height $30 \mathrm{~cm}$ (B) Pongamia seed development. Mature seed develops I0-II months after flowering. (C) Mature pongamia seeds from elite tree. Each weighs about 2.5-3.5 g dried. (D) Pongamia seed oil analysis during develpment. Represented fatty acids are coupled in oil as triglycerides. Free fatty acid content is very low. (E) Pongamia seed section. Major cellular components are oil droplets (O; total mass about $35 \%-45 \%$ of total), protein particles ( $p$; containing mainly storage protein PpSSP50 [similar to soybean 7S beta-conglycinin], and starch granules [S]). Size of shown cell is about 80 microns. (F) Pongamia nodulated root system (from seedderived plantlet). Age 8 weeks after germination and concurrent inoculation with Bradyrhizobium japonicum. (G) Rooted cutting used for clonal reproduction. Usually semiwooded explant material with at least one leaf node is used. Smaller explants work as well. (H) Pongamia shaker harvester. This worked effectively for seed harvest of pongamia trees grown in the Brisbane area; seeds are ready for harvest usually around November/December in the southern hemisphere. Optimization is anticipated with a need for manufacturer involvement for the specific crop. Arrow indicates the tree trunk. (I) Mature pongamia tree (7 years old, $5 \mathrm{~m}$ tall, and $15 \mathrm{~cm}$ trunk) growing on the UQ campus Brisbane. The tree (UQ-I) is source of the chloroplast and mitochondrial genome data as mentioned in Kazakoff et al. ${ }^{23}$ Abbreviations: UQ, The University of Queensland; min, minutes.

mass than single-seeded pods. The seed takes 10-11 months to mature (Figure 1B), meaning that harvesting (by canopy disturbance with mounted rods or tree shaking commonly seen with harvests of olives or macadamia nuts) frequently occurs during early flowering time for the following season's crop. This bottleneck can result in a yield penalty because of physical damage to emerging flowers.

Pongamia seeds are somewhat difficult to germinate. It is best done with young seeds. Storage $>3$ months tends to lower the frequency of germination and older seeds (6-12 months old) can be nearly nonresponsive. Such viability loss may be caused by oxidation of oils and fatty acids in the oil-rich seed.

Germination is best achieved at $28^{\circ} \mathrm{C}-33^{\circ} \mathrm{C}$. Seeds are imbibed in fresh water with coverage by water not exceeding the mid-line of the seed. In other words, oxygen appears to be useful during these early periods of germination. The imbibed seeds (swollen to twice the volume) are then transferred once or twice to fresh water over the next 2 days, before being planted in soil substrate in a vertical orientation with the embryo downward to enable the emerging tap root to penetrate the soil; such seeds are maintained at $28^{\circ} \mathrm{C}-30^{\circ} \mathrm{C}$ and well watered as needed. Germination does not extend the hypocotyl leaving the two seed halves at soil level, with the epicotyl extending as the shoot/stem component of the plant (Figure 1A). Growth is rapid with 3-week-old seedlings reaching a height of $15-25 \mathrm{~cm}$.

\section{Pongamia seed content}

Pongamia seeds vary in size and composition, depending on the genetic make-up of the mother tree. Interestingly, one notes that all pods on any one tree have more or less the same 
shape, color, and seed size (Figure 1C). In other words, these pod and seed traits appear to be maternally controlled (as the individual embryos in each seed themselves are genetically different caused by segregation and predominant outcrossing using insects like bees). ${ }^{16}$

A 6-7-year-old pongamia tree growing in subtropical Queensland in essentially perfect conditions will develop 10-20,000 pods/year. Annual variation does occur with some trees, although some elite trees, targeted to be maintained as clones, show consistent annual yields that are subject to environmental limitations (such as storms and rain at flowering time and general water supply).

Pongamia seeds contain nonedible vegetable oil (a $35 \%-45 \%$ range is normal) and storage protein $(20 \%$ of seed dry weight; the majority being a single protein type of low nutritional quality highly related to soybean $7 \mathrm{~S}$ beta-conglycinin). Our research group has cloned the relevant PpSSP50 gene from pongamia. We also completed oil analysis and found that it is composed of triglycerides predominantly containing the monounsaturated C18:1 (oleic acid; $50 \%-55 \%$ ), with only minor amounts of palmitic (C16:0) and stearic (C18:0) fatty acids (Figure 1D). Each of these saturated fatty acids amounts to no more than $10 \%$, giving the pongamia oil a functional cloud point of $\sim 2.5^{\circ} \mathrm{C}$. This gives excellent assurance to mixtures of pongamia oil or biodiesel with other liquid fuels (eg, a B20 mix containing $20 \%$ pongamia-derived biodiesel) against engine congestion, malfunction, or low effectiveness.

The remnants of the pongamia seed are yet undescribed carbohydrates, such as starch and sugars (as seen in the microscopic section of a near-mature seed; Figure 1E).

\section{Genetic and phenotypic diversity}

Pongamia is a predominantly outcrossing species (insect facilitated), resulting in genetically divergent progeny (Jiang et al, unpublished data, 2014). ${ }^{14,17}$ Thus, wild trees develop flowers and yield seed at different times. This variability is seen as both a challenge and an opportunity. Advantages from genetic diversity are seen with phenotypic diversity with trees suited to local conditions can be selected and propagated by clonal reproduction methods for selected (and patented) varieties. Field tests of such clones show strong uniformity in phenotypes, such as flowering time, seed size, pod shape, leaflet number ( 5 vs 7), nodulation (Figure 1F), and even tree architecture (erect vs prostrate).

The negative aspects come as issues related to development and disease susceptibility. Pongamia, like all organisms, is potentially affected by disease of every organ; insects attack leaves and even flowers, larvae as part of the insect's life cycle alter tropical pongamia flowers into cherry-like balls, and fungal blemishes are commonly seen in late season on leaves of mature trees. Abundance of clonal material, such as in a plantation of thousands of trees, potentially supports the rapid expansion of disease-causing organisms. Thus, clones are excellent for constancy of growth and yield but are potential disasters, if subject to a major disease. The 1971 US corn blight is an excellent example of crop failure (70\% was lost), because of a common genetic background.

A second negative aspect of clones is that adventitiously rooted cuttings have more horizontal than vertical root architecture (Figure $1 \mathrm{G}$ ). These roots function perfectly well but will not easily explore deeper soil. Thus, compacted ground will lead to more subsurface-based roots, increasing dehydration pressure, and need for irrigation. For production-focused field plantation, we solved this situation by predrilling the planting holes, rather than using ripped furrows, supported by weed mats and support stakes at a trial of pongamia on a coal mine rehabilitation site (near Kingaroy, Queensland; Figure 2).

\section{Pongamia flowering}

Normal annual flowering in the south-east Queensland, Australia region occurs from mid-October to mid-November, although flowering is observed with some trees as late as January. Some trees in some locations flower twice per year (a clear photoperiod response). However, flowering generally occurs once per year, resulting in annual seed crops obtained by mechanical harvesting (Figure $1 \mathrm{H}$ ) with machinery developed for olive or macadamia nut harvests.

Flowering efficiency (number of flowers developed per tree) and fertilization success (judged as percentage of flowers with pod) will vary depending on the climatic conditions (temperature, rain, insect presence, and pest pressures) and the tree's genotype. For example, conditions such as persistent spring rain limit the activity of the fertilizing insect, thereby restricting pod set from flowers. Numerous florets ( $\sim 50$ at different stages of development and thus degree of readiness for fertilization) on the individual fluorescence seem to be in the receptive stage for just a few days, although flowers as a whole are present for 14-20 days (depending on climatic conditions). Under optimal spring conditions, pongamia trees develop clusters of pods resulting in higher yields per tree.

The wide-scale use of vegetative clones is seen as a tool to overcome the inherent genetic diversity of pongamia seeds and resultant seed-bearing trees. Clones of elite single trees have been obtained by various techniques, such as vegetative 

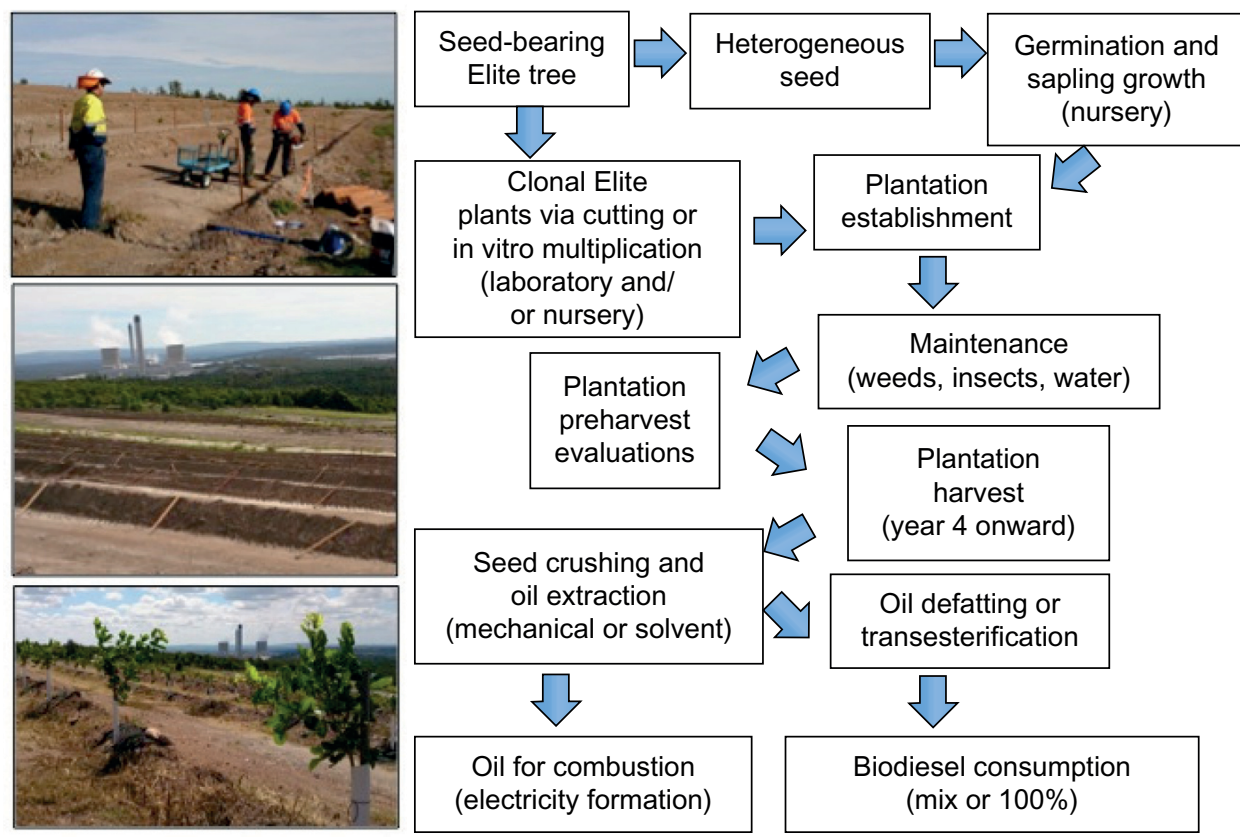

Figure 2 Pathway to pongamia biofuel production.

Notes: Left: three stages of establishment of plantation in difficult soil. Example from the Meandu Coal Mine near Kingaroy (Queensland) owned by Stanwell Corporation planting being done by BioEnergy Australia Pty Ltd (part of ARC Linkage grant) with CILR (UQ) and Stanwell Corporation staff. Plantation tests were established to evaluate the suitability of pongamia for rehabilitation, stabilization, and reforestation of coal mine spoils. Biofuel production is seen as an additional outcome. (Note the sculptured soil preparation to increase water retention in the arid Queensland interior.) Right: the overall pathway toward biofuel (oil and biodiesel) production from Pongamia. Elite trees with superior traits are selected in Queensland as source of either heterogenous seed populations or clonal material (rooted cuttings or cell culture propagules). These are raised in nurseries to get established saplings (70-90 cm tall; within 7-10 months). These are planted at $\sim 450-600$ saplings/ha. Irrigation is needed if insufficient rainfall or extended drought periods are expected. Preharvest evaluation occurs in the first 3-4 years, as some trees would already have fruited. Proper harvest occurs from the fourth year onward. First harvests are small and commercially insufficient but allow system development (crushing and transesterification). Final products (oil itself and converted biodiesel) are expected for commercial use by year 6 .

Abbreviations: ARC, Australian Research Council; CILR, Centre for Integrative Legume Research; UQ, The University of Queensland.

cuttings and induced root formation. This procedure is technically simple but made complicated, as some elite trees do not easily form roots on cuttings, despite hormonal (indole butyric acid) stimulation. The reasons for this diverse response are not yet known and require further investigation.

Another approach for vegetative reproduction of pongamia involves aseptic tissue culture. ${ }^{18}$ We excised the growing apical tip ( $\sim 1 \mathrm{~mm}$ length) of pongamia branches and then cultured these on defined tissue culture media supplemented with phytohormones (Jiang and Biswas, unpublished data, 2015). The shoot-tip produced an abundance of lateral organs along its interface with the medium in 6-8 weeks. These developed as shoot-tips and could be easily separated to form individual plantlets. Culture on a diluted nutrient medium induced adventitious roots, allowing the plantlet to be placed in soil-filled pots for later field evaluation: it was possible to multiply one shoot-tip into 10 to 20 clonal copies. Clonal identity was verified by molecular markers (Figure 5 in Jiang et $\mathrm{al}^{16}$ ). The procedure is time-consuming ( $\sim 12$ months needed for plants ready to be planted) and costly, as sterility needs to be maintained while in culture.

\section{Pongamia molecular genetics}

Genetics and genomics studies of P. pinnata are in their early stage. Pongamia is outbreeding, resulting in genetically diverse progeny seed (and resultant sapling and trees). Tree diversity has been monitored using molecular markers. ${ }^{16,19}$ The general tree population of pongamia in the city of Brisbane is $\sim 20,000$, being planted by the city for street and park horticulture. The tree is sturdy, has dark green foliage, produces beautiful pink, white and light blue/purple flowers over a prolonged period (Figure 1I, 6-7 year-old tree in front of the authors' Brisbane laboratory).

The wide phenotypic diversity of pongamia can be discovered by simple and random observation of Brisbane street and park trees. Some of that is caused by trees seemingly (by phenotype of leaf shape and tree structure) related to northern Australian trees growing in large wild populations near Cooktown (far-north Queensland). DNA from pongamia trees in Malaysia and India was categorized among the local Brisbane samples, suggesting that most Brisbane street trees were introduced some 20-40 years ago from material anywhere in south-east Asia. Sadly, the Brisbane City Council has no record for the origin of the planted material. 
We conclude that Brisbane city trees are of various, although predominantly south-east Asian and even Indian origins. Furthermore, we propose that northern Queensland trees of $P$. pinnata are native and of non-human plantings. This explains the distinct phenotypic classification of elongated leaf shape, smaller pod and seed size, and more erect tree shape. ${ }^{16}$ Field observations close to Cooktown indicated indistinguishable flower morphology relative to the Brisbane type but distinct differences in seed size and indeed overall seed set (Gresshoff, unpublished data, 2014).

The pongamia tree is a true diploid, showing 22 chromosomes $(\mathrm{n}=11)$, which are very small with a size equivalent to soybean (Glycine max) mitotic metaphase chromosomes and a nuclear DNA content of 2.51 pg per $2 \mathrm{C}$ nucleus. ${ }^{20}$ This is equivalent to 1,191 Mbp per haploid genome. This is confusing because this genomic value is almost equivalent to that of soybean; yet the haploid genome of soybean contains 20 chromosomes, compared to eleven for P. pinnata. Given the similar visual size after staining at metaphase, one wonders whether the analysis was affected by the in vitro nature of the analyzed roots. ${ }^{20}$ However, analysis of normal seedlingderived roots confirmed the nuclear DNA content (Rangan, unpublished data, 2016), indicating that visual estimation of nuclear DNA content from condensed metaphase chromosomes is open to misestimations.

Recent work in our laboratories led to the isolation of several target genes of pongamia. Deep sequencing of pongamia DNA allowed the characterization of several flower control genes, including those encoding Constans-like (Kamde et al, unpublished data, 2016), uricase, fatty acid biosynthesis enzymes (such as PpFAD2 ${ }^{21}$ ), and the seed storage protein PpSSP50. Specifically, the identification of four pongamia circadian clock genes (ELF4, LCL1, PRR7, and TOC1) was described through the mapping of the pongamia transcriptome short-paired reads library (produced by Illumina ${ }^{\mathbb{R}}$ sequencing), by using soybean circadian clock genes as the reference sequences. ${ }^{22}$ Furthermore, multiple alignments and phylogenetic analyses suggested that pongamia clock genes are conserved among legume crops, such as soybean, medicago, and garden pea. Gene expression studies highlight that pongamia circadian clock genes are diurnally regulated under long-day conditions. In general, sequence homology to soybean is between $70 \%$ and $80 \%$, allowing rapid detection of candidate sequences based on verified soybean genes in our Illumina ${ }^{\circledR}$ database.

Significantly, the Illumina ${ }^{\circledR}$ sequencing resulted in an abundance of reads for organelle DNA. Thus, Illumina ${ }^{\circledR}$ Second Generation DNA Sequencing (2GS) and a new short-read de novo assembler, SaSSY, were used to assemble and annotate the pongamia chloroplast $(152,968 \mathrm{bp}$; cpDNA) and mitochondrial ( $425,718 \mathrm{bp}$; mtDNA) genomes. ${ }^{23}$ The cpDNA was highly conserved relative to those of other legumes, such as Vigna radiata and the model legume Lotus japonicus. The pongamia cpDNA contains 77 unique protein-coding genes and is almost $60 \%$ gene dense. It contains a $50 \mathrm{~kb}$ inversion common to other legumes, as well as a novel $6.5 \mathrm{~kb}$ inversion that is responsible for the nondisruptive, reorientation of five protein-coding genes. In addition, two copies of an inverted repeat firmly place the species outside the subclade of the Fabaceae, lacking the inverted repeat. In contrast, we found the mtDNA to be gene poor with only 33 unique proteins being encoded.

These genomic findings increase understanding the energy metabolism of $P$. pinnata. Tools, approaches, and composition data all help to develop the future steps needed to improve the performance of this already well-adapted tree.

\section{Conclusion}

It is well accepted that the $P$. pinnata tree has immense potential as a biofuel feedstock, capable of producing large amounts of plant-derived oil useful for direct energy production or conversion into biodiesel and aviation jet fuel (Figure 2). ${ }^{3,8}$ The legume nature of the tree is beneficial as nitrogen fertilizer needs are reduced. Likewise, the tree enters into a symbiosis with mycorrhizal fungi, leading to reduced phosphorus demands.

Sadly, most of the biofuel applications of pongamia seed are at a "village level" or in the hypothetical and predictive writings of scientists and investors and not industrial workers. We all realize that our biological and genetic knowledge has selected tree germplasm that produces reliably large amounts of seed oil. We understand many of the silvicultural parameters for reliable cultivation. Conversion into fuels is done by the described processes.

Presently (late 2015), the value of crude oil is surprisingly low ( US\$45 per barrel of West Texas Crude). This does not foster the general mindset for more investment into renewable biofuels. Indeed, one hopes that investors recognize that this is short termed as the liquid fossil fuel supplies are limited. We totally agree that biofuels, even if derived from the most promising plant crops, cannot supply the entire global energy need. However, if managed properly, they can be part of the spectrum of energy sources. The complexity of that spectrum is beyond speculation, but one can see the advantages of using a feedstock that has biological attributes lessening the energy-dependent inputs (such a nitrogen fertilizer). 
Biofuel researchers recognize that their product, just like coal or liquid fossil fuel, releases $\mathrm{CO}_{2}$ when combusted. However, in contrast to the fossil fuel, that $\mathrm{CO}_{2}$ was assimilated by the natural process of photosynthesis, leading to the synthesis of sucrose, which in turn produced the fatty acids being part of the plant oil. Thus $\mathrm{CO}_{2}$ release is neutral, compared to the negative effects of burning the coal, gas, or oil that was deposited after $\mathrm{CO}_{2}$ capture millions of years ago. In addition, the pongamia biofuel is not plagued by undesired emission components, making it an attractive fuel of the future. Clearly optimistic and far-reaching investment and associate research support will result in a quicker realization of these potentials.

\section{Acknowledgments}

We thank the Australian Research Council for provision of Australian Research Council Linkage grants (in partnership with BioEnergy Plantation Australia and Stanwell Corporation). ARC and the University of Queensland also provided funds through the ARC Centre of Excellence for Integrative Legume Research grant. We also thank TerViva Company in California, especially its main staff Dr David Harry and CEO Mr Naveen Sikka, the Brisbane City Council, and the Global Change Institute as well as the Queensland Smart Futures grant.

\section{Disclosure}

The authors report no conflicts of interest in this work.

\section{References}

1. Whitmee S, Haines A, Beyrer C, et al. Safeguarding human health in the Anthropocene epoch: report of the Rockefeller Foundation-Lancet Commission on planetary health. Lancet. Epub 2015 July 15.

2. Biswas B, Kazakoff SH, Jiang Q, Samuel S Gresshoff PM, Scott PT. Genetic and genomic analysis of the tree legume Pongamia pinnata as a feedstock for biofuel. Plant Genome. 2013;6:3.

3. Scott PT, Pregelj L, Chen N, Hadler JS, Djordjevic MA, Gresshoff PM. Pongamia pinnata: an untapped resource for the biofuels industry of the future. Bioenerg Res. 2008;1:2-11.

4. Kazakoff S, Gresshoff PM, Scott PT. Pongamia pinnata, a sustainable feedstock for biodiesel production. In: Halford N, Karp A, editors. Energy Crops. Cambridge, UK: Royal Society of Chemistry; 2011:233-254.

5. Jensen ES, Peoples MB, Boddey RM, et al. Legumes for mitigation of climate change and provision of feedstocks for biofuels and biorefineries. Agron Sustainable Dev. 2012;32:329-364.
6. BP Website [webpage on the Internet]. Oil: Review by Energy Type. 2015. Available from: http://www.bp.com/en/global/corporate/about-bp/ energy-economics/statistical-review-of-world-energy/review-byenergy-type/oil/oil-reserves.html. Accessed December 18, 2015.

7. Williams SJ, Gresshoff PM. The good oil. Australas Sci. 2006; 27(10):34-36.

8. Murphy HT, O'Connell DA, Seaton G, et al. A common view of the opportunities, challenges and research actions for Pongamia in Australia. Bioenerg Res. 2012;5:778-799.

9. Gresshoff PM. The contrasting need for food and biofuel: can we afford biofuel? A Love of Ideas. Sydney, New South Wales: Melbourne University Press; 2014:144-152.

10. Gresshoff PM. Modern biology analysis of the legume tree Pongamia pinnata as a sustainable biofuel source. Legume Perspect. 2015;6:25-28.

11. Ferguson BJ, Indrasumunar A, Hayashi S, et al. Molecular analysis of legume nodule development and autoregulation. $J$ Integr Plant Biol. 2010;52:61-76.

12. Klein-Marcuschamer D, Turner C, Allen M, et al. Technoeconomic analysis of renewable aviation fuel from microalgae, Pongamia pinnata, and sugarcane. Biofuels Bioprod Biorefin. 2013;7(4):416-428.

13. Samuel S, Scott PT, Gresshoff PM. Nodulation in the legume biofuel feedstock tree Pongamia pinnata. Agron Res. 2013;2:207-214.

14. Biswas B, Gresshoff PM. The role of symbiotic nitrogen fixation in sustainable production of biofuels. Int J Mol Sci. 2014;15:7380-7397.

15. Kesari V, Ramesh AM, Rangan L. Rhizobium pongamiae sp. nov. from root nodules of Pongamia pinnata. Biomed Res Int. 2013;2013:9.

16. Jiang Q, Yen S-H, Stiller J, Edwards D, Scott PT, Gresshoff PM. Genetic, biochemical, and morphological diversity of the legume biofuel tree Pongamia pinnata. J Plant Genome Sci. 2012;1:54-68.

17. Gresshoff PM, Hayashi S, Biswas B, et al. The value of biodiversity in legume symbiotic nitrogen fixation and nodulation for biofuel and food production. J Plant Physiol. 2015;172:128-136.

18. Biswas B, Scott PT, Gresshoff PM. Tree legumes as feedstock for sustainable biofuel production: opportunities and challenges. J Plant Physiol. 2011;168:1877-1884.

19. Kesari V, Sathyanarayana VM, Parida A, Rangan, L. Molecular markerbased characterization in candidate plus trees of Pongamia pinnata, a potential biodiesel legume. AoB Plants. 2010;plq017.

20. Choudhury RR, Basak S, Ramesh AM, Rangan L. Nuclear DNA content of Pongamia pinnata L. and genome size stability of in vitro-regenerated plantlets. Protoplasma. 2014;251:703-709.

21. Ramesh AM, Singh A, Shelke RG, Scott PT, Gresshoff PM, Rangan L. Identification of two genes encoding microsomal oleate desaturases (FAD2) from the biodiesel plant Pongamia pinnata L. Trees 2016;30(4):1351-1360.

22. Winarto HP, Liew LC, Gresshoff PM, Scott PT, Singh MB, Bhalla PL. Isolation and characterization of circadian clock genes in the biofuel plant Pongamia (Millettia pinnata). Bioenerg Res. 2014;8(2):760-774.

23. Kazakoff SH, Imelfort M, Edwards D, et al. Capturing the biofuel wellhead and powerhouse: the chloroplast and mitochondrial genomes of the leguminous feedstock tree Pongamia pinnata. PLoS One. 2012;7(12):e51687.
Energy and Emission Control Technologies

\section{Publish your work in this journal}

Energy and Emission Control Technologies is an international, peer-reviewed, open access journal publishing original research, reviews, editorials and commentaries on developing technologies to optimize energy production and control of emissions. The manuscript management system is completely online and includes

\section{Dovepress}

a very quick and fair peer-review system, which is all easy to use. Visit http://www.dovepress.com/testimonials.php to read real quotes from published authors. 